\title{
Article Errors in the English Writing of Saudi EFL Preparatory Year Students
}

\author{
Eid Alhaisoni (Corresponding author) \\ Department of English Language, University of Ha'il, Saudi Arabia \\ E-mail: eid.alhaisoni@gmail.com \\ Daya Ram Gaudel \\ Department of English Language Skills, Deanship of Preparatory Year, University of Ha'il, Saudi Arabia \\ E-mail: dayagaudel@gmail.com \\ Khalid M. Al-Zuoud \\ Department of English Language Skills, Deanship of Preparatory Year, University of Ha'il, Saudi Arabia \\ E-mail: krashed97@yahoo.com
}

Doi:10.7575/aiac.alls.v.8n.1p.72

URL: http://dx.doi.org/10.7575/aiac.alls.v.8n.1p.72
Received: 03/10/2016

Accepted: 26/12/2016

\begin{abstract}
This study aims at providing a comprehensive account of the types of errors produced by Saudi EFL students enrolled in the preparatory year programe in their use of articles, based on the Surface Structure Taxonomies (SST) of errors. The study describes the types, frequency and sources of the definite and indefinite article errors in writing compositions. Data were collected from written samples of 150 students. They were given one-and-a-half hours to write on one of four different descriptive topics. Analysis of inter-lingual and intra-lingual sources of article errors revealed that the frequency of eliminating both the indefinite articles and the definite article was higher than the frequency of inserting and substituting one article with the other. The study also shows that errors of using ' $a$ ' were more common than errors of using 'an' and 'the' in the writing texts. This result also indicates that L1 interference strongly influences the process of second language acquisition of the articles, having a negative effect on the learning process Pedagogical practices including comparison of article use in learners' both language systems may improve learners' ability to use the articles correctly in writing and the other language skills.
\end{abstract}

Keywords: error analysis, omission, insertion, substitution, interlingual, intralingual

\section{Introduction}

Within the field of second language research (SLR), a large number of studies have focused on error analysis. In general terms, errors have long held the fascination of language instructors and researchers. According to Corder (1967) errors were considered a problem that should be eradicated as soon as possible. However, errors are now looked on as adevice that can assist in the learning process. They provide evidence of the learner's level in the target language, as stated by Gass and Selinker (1984). Moreover, AbiSamra (2003) pointed out that errors also contain valuable information on the learning strategies of learners. Richards (2002) mentioned that in the speaking or writing of a second or foreign language, an error is the use of a linguistic item (e.g. a word, grammatical item, speech act, etc.) in a way which a fluent or native speaker of a language regards as faulty or incomplete. Error analysis, an important aspect of language learning, has a vital role in studying the processes that go beyond the understanding of using articles. Master (1997) argues that, "imperfect control [of the use of articles] may . . Suggest imperfect knowledge." Using articles correctly is evidence of mastery of the language. Hewson (1972) also emphasized the importance of using articles and he noted that "the definite and the indefinite article are among the ten most frequent words of English discourse".

Thus, conducting error analysis is one of the best ways of describing and explaining errors made by ESL/EFL learners. This kind of analysis can reveal the sources of these errors and the causes of their frequent occurrence. Once the sources and causes are exposed, it will be possible to determine the remedy, as well as the emphasis and sequence of future instruction.

Most EFL students regarded using articles are a challenge for them. Most of the studies about errors in usage of English articles have classified them into general categories. Corder (1967) developed error analysis (EA) to study the causes and the classification of errors into the following categories:

- Linguistic level (pronunciation, grammar, and vocabulary)

- Form (omission, insertion, transposition, and substitution) 
- Modality (level of proficiency in speaking, reading, writing, and listening)

- Cause (interference, interlingual)

- Norm versus system

EA theory has helped researchers to identify and investigate the causes that underlie article use errors. Moreover, research based on EA theory enabled them to classify errors into different categories and calculate the percentages of each type, which provided researchers with a broad knowledge about errors and their sources. Corder (1967) stated that "systematically analyzing errors made by language learners makes it possible to determine areas that need reinforcement in teaching" (pp. 161-169). This shows the importance of EA in facilitating English language acquisition.

The current study aimed at categorizing errors into four types, namely, substitution, insertion, omission, and transposition, whereas the cause level of errors shed light on interference and interlingual sources of errors. Vadatinejad (2008) investigated the role of EA in providing learners with the most important things that the learner has to learn and providing him/her with the necessary performance-related information. Teachers often obtain information about the progress of the students in English language learning; students obtain sources for learning the language; and researchers gain an understanding of the language acquisition process. EA has an impact on language acquisition theory and second language writing instruction.

\section{Literature Review}

In reviewing the literature, we found that there is a scarcity of studies that tackled the investigation of article misuse by Arabic-speaking EFL students. Tracing the studies about articles led us to examine Arab students' misunderstanding of the usage of articles in their composition.

Alhaysony (2012) studied the types of errors committed by 100 first-year Saudi Female EFL students in their writing compositions. Results showed that omission of 'the' article surfaced more frequently errors than substitution errors. AlMohanna (2014) analyzed Saudi university EFL students' compositions to establish the types of the article errors in writing. The researcher used contrastive analysis and error analysis in identifying, classifying, analyzing and explaining students' errors. This study identified six types of errors which included omission of 'a' and 'an', wrong use of the articles for nouns and adjectives, substituting ' $a$ ' and 'an' for 'the', substituting 'the' for ' $a$ ' and 'an' or eliminating the articles and inserting 'a' or 'an' erroronously before uncountable nouns. The researcher concluded that most of the errors were the products of overgeneralization and interlingual nature.

Tawalbeh (2013) used a translation test and a gap-fill test to examine the influence of informal Jordanian Arabic on the use of negation and definite articles in English. The total 200 Jordanian (100 male and 100 female) students were randomly selected from public schools in the region of Karak-Jordan. The study results showed that students have a clear problem in using definite articles and English negation due to the use of informal Jordanian Arabic. These results shed light on the effect of Colloquial Saudi Arabic on the transferr of errors between the Arabic and English languages.

Crompton (2011) studied the article errors in a corpus of English writing of advanced L1 Arabic speakers including the comparision of the rate of article errors of native English and non-native English speakers. The study revealed that misuse of the definite article is the commonest error in both making L1 transfer as the main cause for these errors. The authors concluded that L1 transfer was a major problem for learning language. Likewise, Prior, Fujise and Fenwick (2014) examined 'the relationship between Japanese students' uses of the English non-generic definite article and the cognitive style of field dependence/independence' (p.217). The sample consisted of twenty-seven Japanese students who completed a non-generic definite article test that involved filling in missing obligatory instances of the. The researchers adopted Liu and Gleason's model (2002), which consisted of four types: 'textual, structural, situation, and cultural' (ibid). They found that students scored much less in the cultural use than in the structural and textual uses claiming that second language learners face particular challenges to learn the cultural use of the articles. Finally, Lee (2013) compared Korean students' articles use in both oral narratives and written narratives explaining that discourse types had a great effect on the indefinite articles and writing activities may be useful source for improving understanding of using the articles accurately in English.

\subsection{The article systems in the Arabic and English languages}

Before presenting a detailed discussion of the results, it is highly important to make clear that English and Arabic are very different languages from two different language families. 'Arabic belongs to the Semitic group of languages. More specifically, it is an off-shoot of the language of South-West Arabia, while English is an Indo-European language' (ElSayed, 1982, p. 180-181). Therefore, the grammatical structure of Arabic is different from that of Indo-European languages such as English. As a matter of fact, these differences were the cause of many errors made by the students. The differences and similarities between Arabic and English in terms of their article systems should therefore be clarified.

There are three different articles in English, the definite article 'the', the indefinite article ' $a$ ' or 'an', and the zero article ' $ø$ '. According to Quirk et al. (1972), 'the' is used with specific nouns, 'a' or 'an' is used with non-specific nouns in the singular, while ' $\varnothing$ ' is used with non-specific nouns in the plural, proper nouns, mass nouns, abstract nouns, and noncount nouns, such as 'rice', 'water', etc.

Nouns used in English might appear in one of three forms: 
1. Singular with 'a/an'; e.g. A horse is a useful animal.

2. Singular with 'the'; e.g. The horse is a useful animal.

3. Plural with zero ‘ø’; e.g. Horses are useful animals.

(Kharama\&Hajjaj, 1989)

Furthermore, they pointed out that an article might modify two nouns conjoined by 'and' if they represent one unit such as 'the father and mother', 'the bread and butter' etc.

In Arabic, the article system is completely different from that of English. While there are three in English, Arabic has only two, the definite article ' $a l$ ', which is a prefix, and the zero or indefinite article, which is simply the absence of the definite article. Regarding the use of the definite article, the main difference between English and Arabic is that Arabic often uses the definite article in contexts where English does not. Kharama and Hajjaj (1989) give some examples as follows:

1. Nouns used generically in Arabic, whether singular or plural, take 'al' (the).

2. Abstract nouns in Arabic take ' al', more frequently than in English.

3. When a mass noun refers to the whole kind, it takes ' $a l$ '.

4. Some proper nouns take 'al', such as 'al-kahera' (*the Cairo).

5. When two nouns are joined by 'and', 'al' is repeated even when these nouns represent one unit such as 'alzawjuwa al-zawjatu' (*the husband and the wife).

6. In some idiomatic forms such as:

A 'malufii Al-lailiwa al-nahaari. $=*$ I work in the day and the night.

Thus, these are the reasons why Arabic learners overuse the definite article when they write in English and make numerous interlingual/interference errors.

\section{Methods}

3.1 Overview

This study aimed at the analysis of the English article errors produced by Saudi students studying English at the Preparatory Year. The following procedures were taken to analyze the data:

1. Identifying the anomalies in the use of articles. This was conducted by a comprehensive analysis of students' writing.

2. Analyzing and categorizing of errors surfaced in the articles use.

3. Counting a frequency of such errors and identifying the sources of the errors.

\subsection{Participants}

A total of 98 male (40.8\%) and female (59.2\%) EFL students studying English at a university in Saudi Arabia participated in the current study. The age of the students ranged from 18 to 25 years, with a mean of 19 years. The participants were selected randomly from four different levels according to their placement test scores. They had received English language education for at least six years in the intermediate and secondary schools before they enrolled in the language course at the Preparatory Year. During a seven-week course at each level, they learnt reading, writing, speaking, listening and grammar skills by both native and non-native English speaker teachers.

\subsection{Data collection}

The participants were assigned to write a composition of approximately 150 words on one of four topics which included:

1. My city

2. My country

3. My favourite team

4. My summer holiday

\subsection{Data analysis}

The researchers classified errors according to the Surface Structure Taxonomy of errors (SST), namely substitution, omission, and insertition errors calculating the number of each type of errors and their percentage. Furthermore, students' errors were categorized into the interlingual errors and the intralingual errors according to their possible sources establishing the the frequency count of errors corresponding to their sources. The analysis of the written samples was carried out applying the contrastive analysis to determine interlingual errors (errors emanating from L1 interference) and the error analysis to determine intralingual errors (errors having no L1 interference). 


\section{Results and Discussion}

A five-step procedure was employed to identify and analyze errors: (1) collection of language samples, (2) identification of errors, (3) description of errors, (4) explanation of errors, and (5) error evaluation (Ellis \&Barkhuizen, 2005).

Table 1. Frequency of errors

\begin{tabular}{lllllll}
\hline Error Types & \multirow{2}{*}{$\begin{array}{l}\text { Number } \\
\text { of errors }\end{array}$} & \multicolumn{3}{c}{ Male (40) } & \multicolumn{3}{c}{ Female (58) } \\
\cline { 3 - 6 } & & Percentage & Number & Percentage & Number & Percentage \\
\hline Omission & 328 & $64.1 \%$ & 190 & $57.9 \%$ & 138 & $42.1 \%$ \\
\hline Insertion & 141 & $27.5 \%$ & 78 & $55.3 \%$ & 63 & $44.7 \%$ \\
\hline Substitution & 43 & $8.4 \%$ & 34 & $79.1 \%$ & 9 & $20.9 \%$ \\
\hline Total & 512 & $100 \%$ & 302 & & 210 & \\
\hline
\end{tabular}

The classification of errors was based on the Surface Structure Taxonomy (SST), involving categorizing errors as either substitution, omission and insertion. Table 1 lists the types and frequency of definite and indefinite article errors and their percentages. The current study primarily aimed to present an analysis of inter-lingual and intra-lingual sources of error in the larger context of written discourse rather than the morphological and syntactic levels. 'Because much of the article system works on a discourse rather than sentence level- sentence level exercises often fail to provide the necessary context for appropriate article selection' (Rinnert and Hansen, 1986: 3).

The analysis of 512 errors related to the definite, indefinite and null $(\varnothing)$ articles in using the English language revealed that the most frequent (64.1\%) errors were omission errors, while insertion errors - redundancy of both definite and indefinite articles - made up only $27.5 \%$ of the total errors identified. Substitution errors represented the smallest proportion, $8.4 \%$. The study also revealed errors related to the indefinite article ' $a$ ' were more frequent than its counterpart 'an.' These results are in line with Alhaysony (2012), who examined article errors of Saudi female students, and found that omission of the articles represented the most frequently occurring errors in her study.

With respect to gender differences, this research also aimed at presenting a comparative study of male and female students' article errors. The overall article error count manifested an interesting phenomenon of male students committing a higher percentage of omission, insertion and substitution errors than their female counterparts. This finding might lend support to the view that male and female learners have differences in language use and language learning strategies, and especially that female learners generally are more socially oriented and engage in interaction more than male learners, resulting in more confidence in language use (Ehrman \& Oxford, 1989). The impact of social interaction on language learning was also demonstrated by Alhaisoni (2012), who established that female students engaged more in interactions and using social networks to support each other in language learning than males, while male students preferred working individually rather than in groups. In Turkey, female students were found to frequently use self-monitoring strategies and they seemed more aware of the need to 'track the source of their important errors in understanding or producing the new language and consequently to try to eliminate such errors' (Kayaoğlu, 2012: 19). In a European study, Vassiliou (2009) reported that girls read more and enjoyed reading more than boys, and girls' achievement in reading was more pronounced than boys'. In this study, too, reading may potentially be responsible for the higher frequency of accurate article use in the female students' target language than their male counterparts. The other influence of male students' higher frequency of article errors observed in the current study could be that males may have a more negative view of foreign language learning and less aptitude than females (Week, 2011).

The following sections will include detailed discussion of each type of error, their sources and implications in English language teaching for beginning learners with Arabic as their native language.

\subsection{Errors of omission}

The results revealed that omission errors, i.e. omitting the definite article 'the' and the indefinite articles 'a' and 'an', where obligatory were the most frequent errors at $64.02 \%$ percent of the total of 512 errors in the analysis of written samples of both male and female students. This finding concurs with Alhaysony (2012), who reported omission of indefinite articles to be the most frequent error in her study of Saudi students. Bukhari and Hussain (2011) also found omission errors (52.63\%) to be the most frequently occurring errors in a study of Pakistani students. In an analysis of gender differences in the use of articles, our study revealed that male students committed higher proportions of omission errors $(57.9 \%)$ than female students (42.1\%). Looking more closely, the omission of the article 'a' before obligatory singular count nouns surfaced more frequently than the omission of its variant 'an' or the definite article 'the'. For example, in sentence constructions such as 'there is garden', 'there is big museum', 'it is big city' or in noun phrases such as 'beautiful city', it is evident that students left out an indefinite article 'a' before the singular noun-'garden', 'big museum', 'big city' and 'beautiful city'. This finding aligns with Al Mohanna (2014), who found Saudi learners of English eliminating a large proportion of indefinite articles (a, an) where obligatory with singular count nouns, and argued that the reason for deviating from the target language use of articles was the non-existence of indefinite articles in the Arabic language. Further, even though the system of marking singular nouns exists in the 
Arabic language, it does not fully correspond with the English article system as an independent entity. For example, in English, 'a' and 'an' are represented as separate independent elements preceding a singular noun or noun phrase such as 'a book', whereas in sArabic this concept is embedded in a noun itself, as in 'kitab' for 'a book'. It may be logical to conclude that a potential source of omission of indefinite articles in the target language in such instances may be inter lingual errors - errors being transferred from their Arabic language system to the target language. Alternatively, proliferation of such errors may also be explained as a result of students' lack of awareness and understanding about the article system in the target language, which differs from that in their native language.

However, as in the English article system in which the definite article 'the' precedes the noun at the initial position, in the Arabic language system 'Al' is used in the same manner. In examining the omission of 'the', for instance in 'Eiffel Tower', 'Red Sea', 'Hospital of King Khalid', 'Kingdom of Saudi Arabia', 'north of Hail', and 'University of Ha'il', students eliminated 'the' before both short and long noun phrases. Such errors could be categorized as intra-lingual errors which include false comparions, wrong analysis, incomplete use of rules, and exploiting redundancy, among others (James, 1998). In exploiting redundancy, in particular, learners often omit grammatical features that do not contribute to the meaning, which might have been a reason for omitting articles in this study as well. Omission of a significant number of articles in this study, therefore, concurs with Mastsuzaki (1998) who contends that 'articles are semantically insignificant and perceptually non-salient, thus not appreciated linguistically' (p.6).

At first it may seem surprising that Arabic speakers would make such errors so often, given that there is an Arabic equivalent to 'the' in English, the'Al' prefix, which precedes proper nouns in instances such as 'Al-hajj', 'Al-Omrah', and 'Al-Abrar Supermarket'. However, the above finding aligns with those of Kharma and Hajjaj (1989), who underscore that the definite article is more frequently used before proper nouns (Al-Riyadh) in Arabic than in English. The subjects in their study still retained 'Al' when embedded in typical Arabic proper nouns and hardly disentangled from them. When we examined the phenomenon of elimination of 'the' before English proper nouns such as 'Red Sea' but use of 'Al' before Arabic proper nouns such as 'Al-Omrah' might be interpreted as EFL learners' tendency to compartmentalize their native language system and the target language system independently. Students may have used the definite article 'the' correctly if they had possessed the knowledge of relationships and connections between the Arabic and English language systems that sometimes overlap and intersect and sometimes do not.

\subsection{Errors of insertion}

Errors of insertion refer to additions of both definite and indefinite articles where they are supposed to be avoided in a well structured sentence in the target language. In this study, insertion errors represented the second highest proportion at $27.5 \%$ (141 errors) of the 512 total errors. The male students made a higher percentage of insertion errors $(55.3 \%)$ than the female students (44.7\%). Interestingly, both male and female students placed the indefinite articles 'a' and 'an' before plural nouns, proper nouns, non-count nouns more frequently than the definite article 'the'. This result does not correspond with Alhaysony (2012), who found the insertion of the definite article 'the' showing up more frequently than the insertion of the indefinite articles ' $a$ ' and 'an' in female Saudi students who enrolled in a sentence and paragraph writing course for English majors. The evidence shows that even in the same EFL context, as a result of distinct proficiency levels, types of article errors made by beginning and elementary writers and advanced writers may differ even while they are accomplishing similar writing tasks. It might be argued that L2 learners' mastery of the English article system develops gradually along with other areas of English language learning. However, Rinnert and Hansen (1986) asserted that 'appropriate use of articles is one of the last aspects of English grammar mastered by most non-native speakers, no matter what their first language is' (3).

In the English article system, 'a' and 'an' are not supposed to precede plural and non-count nouns. However, subjects in our study often made that choice, especially with placing 'a' in front of plural nouns. Common instances such as 'a friends', 'a beautiful cities', 'a people', 'a good players', 'a best players', and 'an awesome players' evidently signal a deviation from the principles governing the use of articles in the English language. In the English language system, the indefinite articles ' $a$ ' and 'an' refer to 'one' and can be used only in front of singular count nouns. When we look further into instances like 'an awesome players', however, we notice that the use of 'an', a variant of 'a', precedes a word beginning with a vowel sound. In other examples above, too, 'a' precedes words beginning with consonants. These instances inform us that although the selection of the indefinite articles depends on the category of the singular noun, regardless of adjectives modifying the noun, there is a certain degree of conformity to the principles governing the use of articles phonologically at the very least. This phenomenon could be explained by virtue of the fact that at their developmental stage of learning the article system, beginning writers may often derive phonological associations earlier than semantic associations of words preceding indefinite articles.

Other instances, for example, 'a New York', 'a Saudi Arabia', 'a money', 'city is a small', 'the Ha'il', represent a deviation from the principles of the article system in English. Though the context warranted the null $(\varnothing)$ article, the subjects placed ' $a$ ' and 'the' randomly in front of these nouns and adjectives. Even when provided the context for writing, beginning learners of English in the current study still lacked awareness and understanding of accurate use of articles manifested by these instances. This finding concurs with Lee (2013), who investigated written discourse by beginners who produced articles with a low rate of accuracy in written discourse, and argues that availability of time and the context provided by written discourse may not be to their advantage. However, she concludes that 'the overall accuracy in the use of English articles was higher in the written narratives compared to the oral narratives' (p.40). 
Substitution errors accounted for by far the least frequent errors in this study, at $8.4 \%$ (34 errors). In contrast to the proportions for omission and insertion errors, male students' errors accounted for $79.1 \%$ of substitution errors whereas the remaining $20.9 \%$ were made by female students, a huge gender discrepancy in proficiency of article use. The first type of error, such as 'a Italian club', where a student substituted 'a' for the accurate indefinite article 'an'. It may be plausible that instances of the indefinite article 'an' are much less frequent than its variant 'a', making 'an' less retrievable than ' $a$ ' from the repertoire of learners' target language. Likewise, in the example 'I went to the restaurant' where a student replaces ' $a$ ' with 'the' when the appropriate usage was 'I went to a restaurant' in the first mention of a restaurant. This result corresponds with Alhaysony (2012) who found that students substituted the definite article 'the' for the indefinite 'a'. Snape (2005) also reported that Spanish speakers learning English substituted the indefinite articles with the definite article and vice versa.

\section{Conclusion}

In conclusion, analysis of omission, substitution and insertion errors in this study informed us that article sources of article errors were both inter-lingual and intra-lingual. If difficulties in using articles are diagnosed as early as possible through the introduction of writing tests, correct intervention methods may be applied to reduce and eliminate learners' article errors. In addition, pedagogical practices including comparison of article use in learners' native language and the target language may improve learners' ability to readily identify differences in article use between their language systems. Further, sufficient practice in using articles at the word and sentence levels and then the discourse level may allow learners to notice the use of articles in a larger context. Next, pedagogical practices of integrating practice in appropriate article usage in reading, writing, speaking and listening tasks may provide learners with further opportunities to see the authentic use of articles. Finally, creating a non-threatening and supportive classroom atmosphere in teaching the grammar of the target language may further improve students' ability and confidence in both accuracy and fluency in the use of articles combined with other linguistic elements.

\subsection{Pedagogical Implications}

We noticed an interesting phenomenon of beginning writers deriving phonological associations earlier than semantic association of words preceding indefinite articles. This may signal that in pedagogical practices involving English indefinite articles, teachers may find it useful first to start teaching vowel and consonant distinctions for words preceding indefinite articles and then the semantic load of words preceding indefinite articles. Similarly, this study also shows that L1 interference exerts a great deal of influence on mastery of the L2 article system. This finding aligns with Alhaysony (2012) who underscores the value of teaching differences between L1 and L2 in the articles usage.

The context provided by writing discourse may not entirely support beginning writers acquiring an understanding of the meaningful context for article use. Therefore, teaching articles with sufficient practice of formulaic chunks and short sentences, dialogues, or cloze tests before presenting written discourse may lead to faster acquisition of fluency and accuracy in article use. For Japanese learners of English, Matsuzaki (1998) proposed 'combination of having learners memorize article phrases and having them familiarized with handy, readily usable rules-of-thumb for the article system' (p.7). This argument is further supported by the findings regarding accuracy in the use of 'Al' before Arabic nouns in the current study. However, Lee (2013) argues that L2 learners of English might produce articles more accurately in the written mode because it allows them sufficient time and cognitive attention for accuracy, and also because it is useful to reduce anxiety while providing meaningful context.

A higher number of errors showing up in the use of indefinite articles may lend credence to the view that teaching of indefinite articles may require more time and attention in the classroom (Lee, 2013). For beginning learners of English, teaching linguistic rules and differences may not be adequate to develop awareness and understanding of the English article system. Integrating practice with indefinite articles into reading, writing, speaking and listening tasks might increase correct use in a meaningful context. It will also offer exposure to instances and practices of the English article system at sentence and discourse levels and facilitate learners noticing how they are used. 'Noticing' is important as a mental activity in working memory to rehearse detected information from the input for learning to occur (Schmidt, 1990).

The main purpose of the current study was to identify the types and sources of article errors in the larger context of written discourse. Alhaysony (2012) believes that Saudi students often lack enough practice in writing, and teachers generally tend to focus on teaching grammar rules over actual writing practice. She recommends the use of proper methods of teaching grammar, adequate writing practice and supporting learners rather than criticizing them for their errors in composition. In addition, we believe that teaching of articles in contexts ranging from smaller units of words and sentences to paragraphs will potentially offer an opportunity for learners to incrementally increase their understanding of the use of articles in context.

\subsection{Limitations of the study}

The current study actually involved production of articles in descriptive discourses, which may yield different results from the use of articles in other forms such as words, sentences, cloze tests or oral production. In addition, the attempt to examine gender differences with respect to article use still remains minimal in the current study, and further research in cognitive psychology and learning strategies influencing proficiency in article use may provide us with a better understanding of the role of gender in proficiency in article use as well as other linguistic elements. 
References

Alhaysony, M. (2012). An analysis of article errors among Saudi Female EFL students: A case study. Asian Social Science, 8(12), 55-66.

Alhaisoni, E. (2012). Language learning strategy use of Saudi EFL students in an intensive English learning context. Asian Social Science, 8(13), 115-127

Al-Mohanna, A.D. (2014). Errors in the usage of the English definite/indefinite articles among Saudi university- level students. International Journal of Arts and Sciences, 7 (3), 79-95.

Bukhari\& Hussain (2011). Error analysis: Learning articles and prepositions among secondary school students in Pakistan. Interdisciplinary Journal of Contemporary Research in Business, 2(12).

Corder, S. P. (1967). The significance of learner's errors. IRAL-International Review of Applied Linguistics in Language Teaching, 5(1-4), 161-170.

Ellis, R., \&Barkhuizen, G. (2005). Analysing learner language. Oxford: Oxford University Press.

Ehrman, M. \& Oxford, R. (1989). Effects of sex differences, career choice, and psychological type on adult language learning strategies.The Modern Language Journal, 73(i).

James, C. (1998). Errors in language learning and use: Exploring error analysis. London: Longman.

Kayaoğlu, M. (2012). Gender-based differences in language learning strategies of science students. Journal of Turkish Science Education, 9(2), 12-24.

Kharma, N. and Hajjaj, A. (1989). Errors in English among Arabic speakers: Analyses and remedy. Longman Group Ltd: Essex, England.

Lee, J. (2013). The Effects of discourse types on the use of English articles by Korean learners of English: Oral vs. written narratives. English Language Teaching, 6 (8), 33-43.

Matsuzaki, T. (1998). An instructional proposal on difficult grammatical features: A case for teaching English articles to adult Japanese learners. Retrieved on April 23, 2015, from:

http://files.eric.ed.gov/fulltext/ED507437.pdf

Prior, S. M., Fujise, K., \& Fenwick, K. D. (2014). Acquisition of the Non-Generic Definite Article in English: The Influence of Cognitive Style. International Journal of Linguistics, 6(3), pp.217-230.

Rahim, M. E. A., Rahim, E. M. A., \& Ning, C. H. (2013). Distribution of Articles in Written Composition among Malaysian ESL Learners. English Language Teaching, 6(10), p149.

Rinnert, C. and Hansen, M. (1986). Teaching the English article system. Japan Association of Language Teachers' International Conference on Language Teaching and Learning. ERIC.

Schmidt, R. (1990). The role of consciousness in second language learning. Applied Linguistics, 11, 129-158.

Snape, N. (2005). Article use in L2 English: Missing surface inflection hypothesis (MSIH) or representational deficit hypothesis (RDH)? Camling. 2005 Proceedings, 159-165.

Tawalbeh, I. Z. (2013). The effect of colloquial Jordanian Arabic on learning the English definite article and negation. English Language Teaching, 6(8), p95.

Vahdatinejad, S. (2008). Students' error analysis and attitude towards teacher feedback using selected software: a case study. Unpublished Master thesis. UniversitiKebangsaan Malaysia, Bangi

Vassiliou, A. (2009). Gender differences in educational outcomes: Study on the measures taken and the current situation in Europe. Education, Audiovisual and Culture Executive Agency (EACEA P9 Eurydice). Retrieved from:

http://eacea.ec.europa.eu/education/eurydice/documents/thematic_reports/120en.pdf

Week, M. (2011). Correlation between foreign language anxiety and gender. Psychology Journal, 8(1), 40-47. 